\title{
VAIDADE E RESSENTIMENTO EM VELHO BRAGA ${ }^{1}$
}

\author{
VANITY AND RESENTMENT IN OLD BRAGA
}

\author{
Priscila Rosa Martins ${ }^{2}$ \\ UEL - Universidade Estadual de Londrina \\ CAPES
}

\begin{abstract}
RESUMO: Sabemos que na escrita literária é possível verificar a manifestação de algumas paixões ou estados de alma, como define Greimas. Na presente análise, detemo-nos primeiramente no tema da vaidade e do orgulho para visualizar como se estruturam as relações entre os atores presentes na crônica "A minha glória literária”, de Rubem Braga, escrita em 1960. Destaca-se que é comum neste gênero haver sincretismo entre narrador e personagem principal devido à preferência pela escrita em primeira pessoa, porém na crônica analisada veremos que é possível articular também uma separação dessas duas instâncias através de embreagens que aparecem no texto, visto que há uma distinção entre o tempo presente da escrita e o tempo da história que é narrada. Após, procuramos demonstrar como estas figuras do tema da vaidade estão relacionadas com o aparecimento do ressentimento na crônica analisada. A fim de fornecer uma amplitude para a análise, recorremos a uma segunda crônica, "Ao respeitável público", de modo a visualizar como o dever-fazer, que neste caso é dever-escrever, está relacionado com o ressentimento e com o crer-ser escritor deste sujeito, ilustrando, mais uma vez, a configuração dos sujeitos do crer e do fazer.
\end{abstract}

PALAVRAS-CHAVE: Vaidade; Ressentimento; Rubem Braga.

ABSTRACT: It is well known that one may find in Rubem Braga's literary writings the manifestation of some moods and passions, as defined by Greimas. In this paper we will firstly analyze the theme of vanity and pride, aiming to visualize how the relations between the characters of "Minha glória literária", written in 1960, are structured. It is of common understanding that there frequently occurs in this literary genre a syncretism between narrator and main character due to the preference of utilizing a first person perspective. Nevertheless, in the analyzed chronicle one may notice that it is also possible to separate these two stances by means of shifting in which takes place in the text through a distinction between the time the work was written and the time period it narrates. Afterwards, we will attempt to demonstrate how the theme of vanity is related to that of resentment in the present chronicle. And, to

1 Este trabalho foi inicialmente desenvolvido para a disciplina Literatura e Poder, ministrada pelo professor Doutor Luiz Carlos Migliozzi. Parte deste foi apresentado na modalidade de comunicação no I Encontro do Grupo de estudos semióticos da UEL, em novembro de 2011.

2 Aluna de Mestrado da Pós-Graduação em Letras, Estudos Literários, da Universidade Estadual de Londrina. Desenvolve pesquisa sobre a obra de Rubem Braga, sob orientação do Professor Doutor Luiz Carlos Santos Simon. Possui Licenciatura em Letras - Língua Portuguesa e Literaturas Vernáculas pela Universidade Federal de Santa Catarina. Contato: catacrese@gmail.com. 
provide a wider range of analysis, we will consider another chronicle, "Ao respeitável público" so as to show how the must-make (in this case, must-write) is related to the subject's resentment and to his belief in being a writer, illustrating once more the configuration of the subjects believing and making.

KEYWORDS: Vanity; Resentment; Rubem Braga.

Na crônica "A minha glória literária" (2005), de Rubem Braga, o narrador conta como foi a primeira vez que vira um texto seu publicado. Diante de tal, relembra que o texto decorrera de uma atividade solicitada pelo professor de Português e segue a narração descrevendo como seu dever deu-lhe reconhecimento como escritor entre os colegas da escola. Durante a narrativa, percebemos que parte desse personagem (aluno Braga) ainda se faz presente no narrador (que chamaremos "velho Braga") e por outras vezes se mostra distante dele.

A crônica inicia com uma citação do texto publicado, o que reforça o sentimento de orgulho que o narrador, ao recontar esta história, ainda sente pela produção. O dicionário Aurélio (1993) define orgulho como "1. Sentimento de dignidade pessoal, brio, altivez; 2. Amor-próprio demasiado; soberba. 3. Aquilo ou aquele(s) de que(m) se tem orgulho" (1993, p.395). Estas três definições do lexema aparecem figurativizadas a partir do tema que poderíamos chamar de vaidade nesta crônica. Para a terceira definição, é possível retomar o que o narrador apresenta após a citação: "Tremi de emoção ao ver essas palavras impressas. E lá estava o meu nome, que pela primeira vez eu via em letra de forma" (BRAGA, 2005, p.380). Nota-se aqui que a importância da publicação não é somente ressaltada pelo objeto-texto, mas sim por ser acompanhada de seu nome, voltando-se para a primeira definição do lexema. Podemos afirmar que já nesse início está marcado uma diferença tênue do que seria "a glória" e depois "minha glória", duas formas que aparecem no texto, pois está relacionada com uma possível gradação e diferenciação deste sentimento de dignidade pessoal.

Retornando ao dicionário, encontramos para glória: "1. Fama obtida por ações extraordinárias, grandes serviços à humanidade, etc.; celebridade, renome. 2. Brilho, esplendor. 3. Honra, homenagem" (1993, p.274). Vemos assim elencadas palavras que apontam para um fim, uma recompensa, uma sanção, o que viria após a performance já realizada; logo, orgulho e glória são instâncias que apareceram após e não antes ou durante a ação. O narrador não deixa de frisar a importância do suporte de publicação, que poderia ser visto como um mero jornalzinho do colégio. Ao acrescentar que "O jornal era $O$ Itapemirim, órgão oficial do Grêmio Domingos Martins, dos alunos do Colégio Pedro Palácios, de Cachoeiro do Itapemirim, Estado do Espírito Santo" (BRAGA, 2005, p.380), descreve a importância de se publicar naquele jornal que fazia parte do seu círculo social e seria lido, hipoteticamente, também por aqueles com quem ele se relacionava na época.

Neste instante, começamos a nos deparar com as figuras da vaidade. O narrador informa que ganhara nota máxima e ressalta: "Não era para menos" (BRAGA, 2005, p.380), e segue citando um parágrafo inteiro da redação que fora publicada. É através dessa citação e da frase acima que percebemos a aproximação entre estes dois sujeitos (o aluno e o

3 Esta opção diz respeito aos estudos de Davi Arrigucci Jr nos quais retrata, no prefácio "Braga de novo por aqui", que Rubem Braga teria adotado este nome para si, em suas crônicas, como um alter ego, de forma a se apresentar como um narrador oral - logo, com experiências a compartilhar - e também para facilitar a aproximação do leitor, que segundo o crítico, criaria "um espaço de intimidade" (Arrigucci Jr, 1988, p.19). Recentemente, Luiz Carlos Simon (2011) também aborda esta opção do autor no artigo "O velho Braga: velho e inquieto".

Disponível em: http://seer.fclar.unesp.br/casa 
velho Braga), porque podemos afirmar que ainda para o velho Braga, seu texto da época da escola é motivo de orgulho. Fica mais claro quando percebemos as debreagens enunciativas que seguem: "eu chamo a lágrima de 'traidora inconsciente dos segredos d'alma', descubro que ela 'amolece os corações mais duros' e também (o que é mais estranho) 'endurece os corações mais moles'. E acabo com certo exagero" (BRAGA, 2005, p.380). Ou ainda quando nos deparamos com os comentários do narrador: "me pus a dizer coisas sublimes", "o importante é que minha composição abafara", "Não me lembro o resto, mas era divino", que parecem trazer para o tempo presente da escrita, logo para o velho Braga, o mesmo prazer de louvor ao verificar que ele (que fora, outrora, o aluno) é também o autor daquele texto. Frisamos nestas citações a frequente escolha pelo tempo presente, além do uso da primeira pessoa do singular, notando que, ao usar o passado, o sujeito das orações é ocultado. Entretanto, é possível perceber que o narrador faz ressalvas à sua escrita de menino, com aparecimento de embreagem: "Sim, eu era um pouco exagerado; hoje não me arriscaria a afirmar tantas coisas" (BRAGA, 2005, p.380).

A publicação do texto no jornal $O$ Itapemirim serve de intensificador para uma espécie de aumento ou gradação da vaidade. É através da publicação que o aluno Braga passa a crer-ser escritor e por isso é deste momento que relembra ao se deparar com seus textos publicados em jornais. Nota-se ainda que, a exemplo do sujeito ressentido, o aluno não tem perfil/competência para escritor, segundo seus sujeitos-julgadores deste momento (os colegas de classe) que passam a desconfiar da autoria do texto. Esta desconfiança não é recebida pelo narrador como sanção negativa, ao contrário, é sentida como positiva e contribui para o aumento do orgulho: "O fato é que a suspeita não me feriu, antes me orgulhou; e a recebi com desdém, sem sequer desmentir a acusação" (BRAGA, 2005, p.380), e a aceita como desafio, provocação: o sujeito se propõe a conquistar novamente o mesmo efeito: "Veriam, eu sabia escrever coisas loucas [...] para embasbacar os incréus" (BRAGA, 2005, p.380-1).

Percebe-se, então, que o professor de Português é, para o sujeito, o verdadeiro sujeito-julgador, é ele que fornece o reconhecimento que o aluno espera. Após o aluno ter recebido a sanção cognitiva positiva dele, que além de avaliar em 10 leu para toda a sala seu texto sobre "A lágrima" ${ }^{4}$, avalia-o positivamente também no próximo texto, com o tema "Bandeira Nacional". Neste momento da narrativa, percebemos mais uma vez a gradação e aumento da vaidade, pois recebemos somente a avaliação do aluno, afirmando que o segundo texto "deixou todos maravilhados" (BRAGA, 2005, p.381). Nesta passagem, o velho Braga, afastando-se do aluno, comenta que esta poderia ter sido menos valorizada, pois "tinha poucas linhas, mas era nada menos que uma paráfrase do Padre-Nosso" (BRAGA, 2005, p.381). O "mas", apesar de ser utilizado para contrapor a sentença que o antecede, aparece para ressaltar o valor de sua originalidade e astúcia de ter feito um grande texto, apesar de curto em se tratando de extensão. Logo, o narrador, neste momento, considera que o motivo de orgulho do segundo texto foi sua ideia inovadora, mesmo que pautada em uma oração. Podemos ainda afirmar que ser conciso não é visto como "defeito" para nenhum dos Bragas.

Lembra-se neste momento que a espera pelo julgamento é tranquila. $\mathrm{O}$ aluno, que já se vê como escritor, não teme a sanção, crê que ela será positiva, por isso, diante das tarefas não demonstra insegurança, receio, angústia. Pelo contrário, expressa felicidade ao ter conhecimento do terceiro tema, "Amanhecer na fazenda", pois se considerava mais que preparado para escrever sobre este assunto: "Ora, eu tinha passado uns quinze dias na Boa Esperança, a fazenda de meu tio Cristóvão, e estava muito bem informado sobre os amanheceres da mesma. Peguei da pena e fui contando com a maior facilidade" (BRAGA,

4 Consideramos que provavelmente indicou para a publicação no jornal do colégio - isto não está discursivizado na crônica.

Disponível em: http://seer.fclar.unesp.br/casa 
2005, p.381). Vemos, nesta passagem, mais uma vez, figuras que representam a vaidade, que remetem à segurança de si próprio. Sobre este lexema, é importante colocar como o dicionário Aurélio define vaidade: "1. Qualidade do que é vão, ilusório. 2. Desejo imoderado de atrair admiração. 3. Frivolidade, fatuidade, presunção" (1993, p.558). Com este dado, retomamos o que afirmamos sobre o perfil/competência do aluno. Segundo o narrador, seus colegas o viam como "tímido e mal falante, meio emburrado na conversa, [...] não parecia capaz de tamanha eloquência" (BRAGA, 2005, p.381). Desta passagem, podemos inferir que seu texto se apresentava como um descompasso de sua aparência, por isso o aluno toma como desafio promover o mesmo resultado nas próximas redações, pois fora o modo de atrair admiração, os olhos de seus colegas para si, que encontrou. À medida que consegue as aprovações, tende a se tornar um sujeito presunçoso e, por este motivo, cada vez mais vaidoso. Podemos afirmar que há o aparecimento da cobiça, porque o narrador ao expressar que para ele os outros se sentiam maravilhados ao ouvir seu texto, crê que eles queriam ser como ele; ou ainda apontar o aparecimento da inveja modalizada em querer-saber ou /querer-ser/ que "implica em querer que o outro não seja" (BARROS, 1990, p.61).

Diana Luz de Barros (1990, p.62) ao descrever alguns percursos das paixões, descreve-as a partir da espera inicial. Seriam duas: /querer-ser/ e /crer-ser/. Sobre este segundo, define:

O sujeito da espera nada pretende fazer parar concretizar suas aspirações e, por isso, mantém com outro sujeito uma relação fundamentada na confiança e crê poder com ele contar para realizar suas esperanças ou direitos, ou seja, atribui ao outro sujeito um /dever-fazer/. O contrato que se estabelece entre os sujeitos é, muitas vezes, um contrato imaginário.

Visto que é através dos textos que o narrador da crônica tem reconhecimento entre seus colegas de classe e quem fornece o reconhecimento é o professor de Português, o programa narrativo seria como prevê Barros:

$$
\mathrm{S}_{1} \text { crer }\left[\mathrm{S}_{2} \text { dever } \rightarrow\left(\mathrm{S}_{1} \cap \mathrm{O}_{\mathrm{v}}\right)\right]
$$

Onde $\mathrm{S}_{1}$ é o aluno Braga; $\mathrm{S}_{2}$, o professor e $\mathrm{O}_{\mathrm{v}}$, reconhecimento.

Como afirma Barros, o /saber poder ser/ sobre modaliza a espera, sendo neste caso analisado na crônica, uma espera relaxada, como a já apontada. A felicidade expressa pelo aluno ao passar saber o tema da terceira redação exprime que o sujeito da espera sabe ser possível a conjunção desejada, porque confia no outro. A confiança, então, aparece relacionada com os dois sujeitos, o aluno que confia em si e confia na avaliação do professor, assim como, o professor confia na capacidade do aluno. Porém, neste momento, a confiança é rompida: o professor expressa sua decepção e ainda ridiculariza o aluno aplicando a mesma conduta - lendo para a classe inteira: "O professor disse que daquela vez o senhor Braga o havia decepcionado, não tinha levado a sério seu dever e não merecia uma nota maior do que 5; e para mostrar como era ruim minha composição leu aquele final: 'um burro zurrando escandalosamente"' (BRAGA, 2005, p.381).

Desta forma, podemos inicialmente esquematizar a crônica desta maneira: o sujeito do fazer é sancionando positivamente por seu julgador, neste primeiro momento há uma espécie de gradação do orgulho próprio, que é aumentado na segunda sanção positiva. Disponível em: http://seer.fclar.unesp.br/casa 
Pode-se ainda incluir que orgulho diz respeito somente ao sujeito do fazer, que após realizar uma performance, sente-se "realizado", orgulhoso do seu feito. Contudo, no segundo momento da narrativa, há uma decepção por parte dos dois sujeitos, ou seja, uma quebra do contrato fiduciário imaginário, quando o aluno não corresponde com a expectativa do professor e, ao mesmo tempo, quando o professor avalia o aluno abaixo de sua expectativa, já que se considerava preparado para tal tarefa.

Sabemos que a sanção aplicada pelo professor é a mesma: ler para a classe com o intuito de fornecer para os outros alunos um exemplo. Sendo esta ação positiva, contribui para vaidade do aluno, pois não só apresenta o reconhecimento do professor, mas também o destaca de seus iguais - ela tem um caráter social. Apesar do segundo texto não ter sido publicado, o narrador-aluno não diminui o seu valor, como vemos nesta passagem: "duas meninas - glória suave! - tiraram cópias, porque acharam uma beleza" (BRAGA, 2005, p.381).

As três composições do tempo da escola ainda são de dar orgulho para o narrador, já que o velho Braga não abre mão de citá-las nem de frisar o valor que cada uma teve. Apesar de não ter sido valorizada pelo professor, a terceira parece conter um aspecto afetivo por relatar uma experiência própria - o que seria motivo de destaque, como apresenta o velho Braga, ou de melhor preparo diante dos outros da classe. Tendo isto em vista, vemos que há uma separação de assuntos: fazer literatura $v s$ contar experiência, considerando que para o professor, esta segunda teria menos valor. Isso marca também a falta de liberdade, ou ainda uma opressão, por parte do sujeito-julgador. Sabemos que as relações escolares proporcionam o surgimento de algumas paixões (muitas vezes provindas dessas opressões e/ou da não-valorização de um aluno por parte do professor/diretor/superiores ou, ao que parece ser o exemplo mais comum, o ato de humilhar um aluno diante da classe inteira) e que estas lembranças, muitas vezes, permanecem no sujeito, mesmo após concluir seus estudos escolares.

O narrador não confessa se após a sanção negativa passou a se sentir inseguro na hora de produzir outros textos. Podemos inferir que não, já que estamos diante da crônica e que ela representa também um texto escrito (como as composições que o professor de Português passava em sala) que também correspondem a um dever-fazer. $\mathrm{O}$ narrador não esconde que se sentiu humilhado: "Foi uma gargalhada geral dos alunos, uma gargalhada que era uma grande vaia" (BRAGA, 2005, p.381), entretanto o velho Braga pode estar atenuando que sentiu vergonha desta situação, afirmando apenas: "Sorri amarelo" (BRAGA, 2005, p.381).

Se considerarmos a distinção que fez Migliozzi (2010) entre humilhação e vergonha, veremos que apesar de sinônimos, aqui seria mais contundente afirmar que o aluno Braga foi humilhado, já que na crônica há pouco direcionamento para a vergonha. É claro que ela existe, mas deixa mais evidente os sujeitos envolvidos nesta ação: o professor humilha o aluno ao ler seu texto (tornando-o público) em sala que, provocando riso nos colegas de classe, atenua a humilhação. Essa afirmação se fortifica se lembrarmos que as considerações de Fiorin (apud MIGLIOZZI, 2010) sobre a vergonha estão relacionadas com o /saber/: o aluno Braga sabe fazer, ou seja, não há uma problematização no ato, na ação. O aluno realizou a tarefa que deveria: fazer a redação, ele não é um sujeito virtualizado. Logo, o aparecimento desta vergonha é retrospectiva:

[...] o evento disfórico [a humilhação] "surpreende o sujeito e o arranca de sua espera relaxada, colocando-o em uma situação intensa, caracterizada pela insatisfação", justamente por não estar conjunto com a boa imagem projetada de si. É quando o sujeito toma consciência de seu papel dentro do Disponível em: http://seer.fclar.unesp.br/casa 
simulacro que projetou para si. Nesse momento, a imagem que o sujeito de estado projetou de si passa pelo "crivo" do sujeito destinador-julgador (MIGLIOZZI, 2010, p.6).

Quanto a esta colocação, relembramos ainda "que a vergonha não ocorre pelo fato de o aluno não saber ou não poder, mas pelo fato desse não saber ou desse não poder tornar-se público" (MIGLIOZZI, 2010, p.3). Mas, se consideramos aqui que o que está posto em evidência é a humilhação devido a não-valorização esperada ocasionando uma honra ferida, podemos falar em ressentimento. Destaca-se que antes de declarar a sanção cognitiva negativa do professor, o narrador declara: "Foi minha desgraça" (BRAGA, 2005, p.381). Se contrastado com sua atitude diante dos colegas, que afirmamos anteriormente, vemos aqui que está discursivizado qual sanção foi mais sentida pelo sujeito.

Os estudos de Fiorin (2007) acerca do ressentimento, baseados nas investigações de Greimas sobre a cólera, apontam para a insatisfação (neste caso, pelo objetoreconhecimento não obtido) e para a decepção (quebra de confiança no sujeito do fazer). Ressaltamos novamente que a decepção, nesta crônica, é uma via de mão dupla: o professor confiou que o aluno faria mais uma produção ao molde das anteriores e esperava que a redação fosse boa segundo seus princípios; e o aluno esperava que o professor o avaliasse positivamente. Aqui retomamos o que havíamos sugerido sobre a competência do aluno, diz Fiorin: "O ressentimento é a paixão dos impotentes, dos fracos [...] Como é moralmente covarde, o ressentido tem duas atitudes: a queixa e a acusação" (FIORIN, 2007, p.16). Neste caso analisado, a forma de operar do velho Braga não deixa de ser um modo que encontrou para se queixar sobre a opressão que sofreu por parte do professor na época da escola. Visto, agora, como um enunciador, sabemos que sua escrita se pauta em suas experiências vivenciadas para produzir suas crônicas. Elas têm destaque em seus textos, pois são geralmente o que propiciam ou o que conduzem a narrativa. Logo, expondo isto para seus enunciatários, pode ser recebida como uma maneira de reequilibrar as paixões, partindo do pressuposto que seus enunciatários também valorizam positivamente este aspecto. Ou seja, a crônica "A minha glória literária" pode ser lida como uma queixa; pois "quando o sujeito tem consciência da falta, ele busca repará-la ou resigna-se" (FIORIN, 2007, p.16).

Apesar de vangloriar-se das redações anteriores, o velho Braga qualifica a primeira como exagerada e a segunda como paráfrase - note ainda, que para a segunda diz: "Não me lembro do resto" (BRAGA, 2005, p.381), sendo possível afirmar que já não marcou tanto quanto a primeira ou a terceira, e perdeu-se no tempo. Se compararmos ainda como o narrador descreve os modos como produziu os textos, veremos que os primeiros pressupõem um rebuscamento, uma "ode a palavra", um modelo, uma cópia. Já o terceiro, visto que parte de suas próprias experiências, retratam originalidade e um experimento com o fazer criativo. Todavia, nesta passagem ainda é possível notar, através da inclusão de uma palavra estrangeira (pendant) ou anteriormente ao referir ao seu texto como "obrinha", o aumento da confiança que tinha em si e uma crença de que havia conquistado sua liberdade de escrita. Entretanto, percebe-se na fala do professor filtrada pelo narrador que a hierarquia entre aluno e professor existe, demonstrada mais explicitamente no momento da reprovação ao se referir ao aluno por "senhor Braga" - mesmo se levarmos em consideração que a referência para o tempo de escola deva ter se passado por meados da década de vinte, do século passado, visto que a crônica traz a data de janeiro de 1960. Lembramos que o ressentido, muitas vezes, é aquele que não consegue aceitar sua posição hierárquica inferior, tanto que nesta passagem ocorre novamente embreagem, com a inclusão de "senhor Braga", logo "ele" e não "eu"; a primeira pessoa só retorna quando se refere à composição. 
Se há uma aproximação, mas existe o distanciamento entre aluno-Braga do velho Braga através das embreagens e debreagens, concluímos que diante do aparecimento do tempo passado, recebemos situações que já não influem na construção desse sujeito que narra sua história no colégio. Logo, ter escrito um texto que foi desaprovado por professor e alunos não é mais motivo de vergonha, porém é um disparador do seu ressentimento, pois é através da escrita da presente crônica que o narrador se afirma novamente como escritor, reestabelecendo as paixões.

Notamos também que após a confissão da vergonha que passou, o narrador volta ao lexema que intitula o texto: "Minha glória literária fora por água abaixo" (BRAGA, 2005, p.381). Glória, neste instante, tem mais relação com seu sentido "primeiro" que enumera o dicionário. Esta glória, do fim do texto, refere-se como o modo que o narrador se refere ao status que obteve com os colegas e professor pelas suas produções nas aulas de Português e se estende até seu segundo sentido, que seria o "esplendor" ou auge/brilho que alcança produzindo o mesmo efeito também na segunda redação. Entretanto, a glória do título da crônica tem mais caráter de "honra, homenagem" por parte do narrador que ao rememorar sua vida escolar relembra justamente sua primeira publicação e o "louvor" que ela lhe propiciou. Pode-se afirmar que é uma "dedicatória" à sua escrita: à "minha" glória literária, que apesar de ter se deparado com algumas dificuldades de reconhecimento, após anos de escrita merece ser respeitada. Aliás, é possível apontar uma nova configuração do programa narrativo: $S_{1}$ passa a ser o enunciador e $S_{2}$ o enunciatário. Lembramos então as considerações de Fiorin: "A finalidade última de todo ato de comunicação não é informar, mas persuadir o outro a aceitar o que está sendo comunicado" (FIORIN, 2006, p.75).

A separação entre fazer literatura $v s$ contar experiência se faz importante nesta crônica pois estes dois pólos fazem parte da escrita do velho Braga, se o considerarmos, neste momento, como um enunciador. Estão relacionados a esta disputa, não só as discussões que surgem quanto ao gênero (crônica - que são textos que, às vezes, são menos valorizados pelos críticos e teóricos por se tratar de publicação no jornal, outras, por estarem intimamente relacionados com a biografia do autor), mas também o debate em torno das definições de história e estória, devido à estreita aproximação ao real e biográfico.

Na crônica "Ao respeitável público" (2002) as projeções do enunciador e narrador estão colocadas de forma mais evidente. Nesta, o narrador afirma que não tem assunto para escrever a crônica, e passa a maldizer seus narratários, já que eles são projeção do sujeito-destinador-julgador e, segundo o narrador, não o sancionariam positivamente, visto que se auto-avalia como um sujeito desatualizado. Entretanto, vale lembrar que estamos diante de uma crônica escrita e que ela aborda sim, um assunto, neste caso: afirmar não ter assunto e, mesmo assim, dever escrever. O percurso narrativo da falta de assunto diante da escrita não se configura como original ou próprio de Rubem Braga, sabemos que muitos autores se utilizam desta perspectiva para escrever. O que chama a atenção nesta é que acaba por se desenvolver também acerca da vaidade e do ressentimento, como na crônica anteriormente analisada. É um interessante objeto de estudo trabalhar justamente com estas narrativas que abordam o dever-escrever para fazer um levantamento dos temas mais recorrentes.

O narrador declara inicialmente: "Chegou meu dia. Todo cronista tem seu dia em que, não tendo nada a escrever, fala da falta de assunto. Chegou meu dia. Que bela tarde para não se escrever!" (BRAGA, 2002, p.24). De antemão, no primeiro parágrafo, vemos no âmbito das oposições categóricas a figura da lítotes: "Quando se nega no enunciado e se afirma na enunciação" (FIORIN, 2006, 81). A recorrência ao uso desta figura no texto é 
grande, como podemos ver: "Não leiam mais"; "Aproveitem este meu momento de sinceridade e não se iludam com o que disser"; "Aqui nesta coluna, eu nunca lhes direi nada, mas nada de nada, que sirva para o que quer que seja. E não direi porque não quero; porque não me interessa; porque vocês não me agradam; porque eu os detesto" (BRAGA, 2002, p.245). Nesta última passagem, há também a manifestação da ironia ou antífrase, pois "se afirma no enunciado e se nega na enunciação" (FIORIN, 2006, p.79), que será frequente quando o narrador se referir aos seus narratários.

No segundo parágrafo há uma enumeração de figuras que poderiam vir a ser o assunto da presente crônica. Esta enumeração é feita, na verdade, pelo enunciador, sem interferências, pois o narrador não as retoma no enunciado:

Esse calor que arrasa tudo; esse Carnaval que está perto, que aí vem no fim da semana; esses jornais lidos e relidos e na minha mesa, sem nada interessante; esse cigarro que fumo sem prazer; essas cartas na gaveta onde ninguém me conta nada que possa me fazer mal ou bem; essa perspectiva morna do dia de amanhã; essa lembrança aborrecida do dia de ontem; e outra vez, e sempre, esse calor, esse calor, esse calor [...] (BRAGA, 2002, p.24; grifos nossos).

É, então, somente no terceiro parágrafo que aparecem os narratários: “meu distinto leitor, minha encantadora leitora, queiram ter a fineza de retirar os olhos desta coluna" (BRAGA, 2002, p.24). Como já afirmado anteriormente, o suposto diálogo com o "leitor" é construído através da antífrase, fornecendo humor ao texto. Todavia, é também através dessa estratégia que percebemos o tema da vaidade, já que, mesmo que o narrador solicite aos narratários para que não o leiam, ele, no decorrer do texto, "constata" que eles seguem com a leitura no sexto parágrafo: "se a senhorita é bastante teimosa, se o cavalheiro é bastante cabeçudo para me ter lido até aqui, pensem um pouco, sejam bem-educados e deem o fora"; e no sétimo: "Mas ainda insistem?" (BRAGA, 2002, p.25-6). Ao contrastar estas duas últimas passagens com a anterior, é possível frisar que há um aumento da vaidade, já que o narrador passa a ter liberdade de maldizer seus narratários; permite, aliás, afirmar que o narrador julga que seus destinadores (narratários) não o compreendem, descredenciando-os, e mesmo que ele os insultem, eles não receberiam, sentiriam como tal. Note ainda que esta estratégia pode ter sido adotada, pois, como já dissemos, o sujeito é desatualizado, configurando-se desta forma:

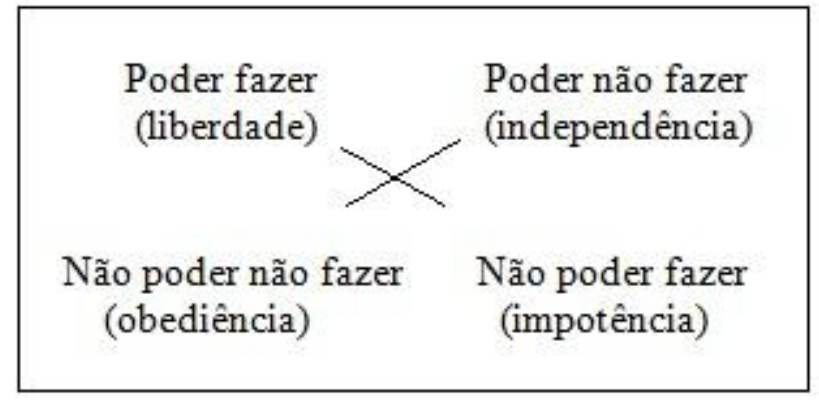

Retornamos, desta forma, ao que havíamos afirmado sobre a falta de liberdade para escrever. Como em "A minha glória literária", nesta presente crônica, o narrador reclama da falta de liberdade de poder fazer o que tem vontade; percebe-se que este impulso inicial é deixado a parte para o narrador passar a se preocupar com sua resposta aos seus narratários. 
Logo, a questão de não ter assunto se transforma em ter assunto e não querer discursivizá-lo, ou seja, ele quer não fazer. Esta atitude retoma as competências do ressentido, considerando o simulacro de que seria sancionado negativamente. Desta maneira, a espera tensa se transforma em insultos, fornecendo características duradouras para este narrador de Braga que mais tarde adota definitivamente a máscara de velho, que também aparecem na crônica anterior. Fiorin (2007, p.16) descreve o ressentido como:

[...] sempre mal-humorado, embora, às vezes, este estado de ânimo manifeste-se como gravidade, circunspecção, austeridade, compostura, seriedade. A sensibilidade ressentida é o domínio dos implícitos, das insinuações, dos silêncios [...] dos subentendidos... Nada é claro.

Em "Ao respeitável público", o narrador opta por discursivizar o não querer fazer e marcar o desvio de assunto para os narratários:

Fiquem sabendo que eu hoje tinha assunto e os recusei a todos. Eu poderia, se quisesse, neste momento, escrever duzentas crônicas engraçadinhas ou tristes, boas ou imbecis, úteis ou inúteis, interessantes ou cacetes. Assunto, não falta, porque eu me acostumei a aproveitar qualquer assunto. Mas eu quero hoje precisamente falar claro a vocês todos. Eu quero, pelo menos hoje, dizer o que sinto todo dia: dizer que se eu os aborreço, vocês me aborrecem terrivelmente mais (BRAGA, 2002, p.26).

É possível notar ainda que há um despertar para a malevolência, pois no decorrer da crônica, o narrador chama a atenção para que caso fosse possível transmitir micróbios através do jornal, ele o faria, assim como encerra a crônica desejando a morte de todos por erisipela ou peste bubônica, e para concluir, expressa seu desejo através de mais uma antífrase: "Passem mal".

À parte do nível narrativo, há que se considerar que este texto pressupõe enunciatários que compreendam a construção irônica, porém o texto não deixa de fechar com a retomada do tema da vaidade, considerando que amanhã os "verá" novamente, da mesma forma que recusar os assuntos se mostra como atitude de rebeldia, procedimento que não poderia ter adotado no seu tempo de escola.

Podemos concluir que as figuras da vaidade aparecem no momento em que ocorre o reequilíbrio das paixões, pois é a forma que o sujeito encontra para questionar sua posição nesta hierarquia. Vale ressaltar que a presente análise tem um caráter sincrônico, já que "Ao respeitável público" foi publicada em 1934 e "A minha glória literária" em 1960. Entretanto, se estamos levando em consideração as modalizações do enunciador em relação à desaprovação do tempo da escola como disparador para o ressentimento, concordaremos que os dois textos têm um passado comum e que podem assim ser lidos à parte das suas construções temporais lineares.

\section{REFERÊNCIAS}

BRAGA, R. A minha glória literária. In: 200 crônicas escolhidas. Rio de Janeiro: Record, 2005. Ao respeitável público. In:

O conde e o passarinho \& Morro do isolamento. Rio de Janeiro: Record,2002. 
CASA, Vol.10 n.2, dezembro de 2012

BARROS, D. L. de. Paixões e apaixonados: exame semiótico de alguns percursos. Cruzeiro Semiótico. n. 11/12, p. 60-73, 1990.

FERreirA, A. B. de H. Pequeno dicionário da Língua Portuguesa. 3.ed. Rio de Janeiro: Nova Fronteira, 1993.

FIORIN, J. L. Semiótica das paixões: o ressentimento. São Paulo: Alfa, 51 (1): 9-22, 2007. Sintaxe Discursiva. In: Elementos de análise do discurso. São Paulo: Contexto, 2006. 14.ed.

MIGLIOZZI, L. C. A vergonha. In: CORTINA, A.; MARCHEZAN, R. C. (Orgs.) Razões e sensibilidade: a semiótica em foco. Laboratório Editorial, FCL, UNESP; São Paulo: Cultural, 2004. 